\title{
Erratum zu: \\ Diffusionsmessung
}

Dennis Bösch, Carl-Peter Criée

\section{Erratum zu:}

Kapitel 6 in: D. Bösch, C.-P. Criée: Lungenfunktionsprüfung., https://doi.org/10.1007/978-3-662-55974-1_6

\section{Es gibt folgende Korrektur auf Seite 133:}

1) Es handelt sich hier um Fallbeispiel 39, nicht 16.

2) Die Abbildung ist falsch (• Abb. 6.3). Anbei die richtige.

$$
\text { Ref. Ist Ist/Ref }
$$

\section{HELILM-RU/FRC}

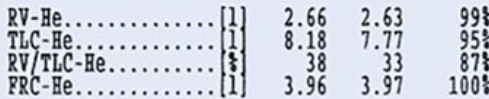

\section{CO-OIFFUSION}

$\begin{array}{lrrr}\mathrm{TLCO} \ldots \ldots \text { [mol } / \mathrm{min} / \mathrm{kPa}] & 11.04 & 12.84 & 1168 \\ \mathrm{RCO} . . . \mathrm{rmol} / \mathrm{min} / \mathrm{kPa} / 1 & 1.38 & 1.67 & 121 \%\end{array}$

$$
\left.\left.\begin{array}{lll}
\text { KA.................... [1] }
\end{array}\right] \quad \begin{array}{ll}
1.38 & 1.67 \\
7.39
\end{array} \quad 121\right\}
$$
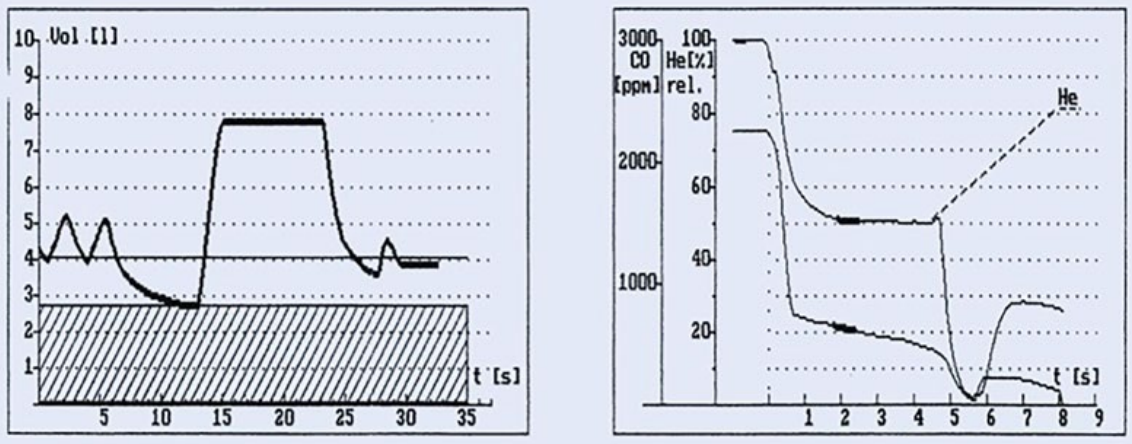

Die aktualisierte Version des Kapitels 6 ist verfügbar unter:

https://doi.org/10.1007/978-3-662-55974-1_6 